\title{
YENI BIR YAŞAM BIÇiMI: ARTIRILMIŞ GERÇEKLIK (AG)
}

\section{Bülent BiNGÖL*}

\section{Özet}

Teknoloji alanındaki gelişmeler/değişimler insan hayatını doğrudan veya dolaylı olarak etkilemektedir. Özellikle iletişim teknolojisi alanında hızla gelişen/ değişen yazılım ve donanımlar insanların yaşama şekilleri, çevresi ile etkileşimi, bireysel zaman geçirme biçimleri üzerinde belirleyici olmakla kalmayıp, insan hayatını ilgilendiren her alanda da etkisini göstermektedir. "Artııımış Gerçeklik (Augmented Reality-AR)" kavramı; sağlık, eğitim, havacılık, savunma, mimarlık, pazarlama, yayıncılık, seyahat, emlak, otomotiv, müzecilik, reklam, eğlence, dijital oyun gibi alanlarda teknolojideki değişime paralel olarak kullanılmaktadır. Teknolojideki bu değişimin görsel ürüne yansımasına en iyi örnek teşkil edebilecek artırılmış gerçeklik, bilgisayar tarafında üretilen ses, görüntü, animasyon, hologram gibi dijital elemanları akıllı telefon, tablet ve sanal gerçeklik gözlükleri sayesinde bulunduğumuz ortamın üzerine gerçek zamanlı olarak yerleştirerek yeni bir algı ortamı oluşturur. Zenginleştirilmiş bu yeni ortam sayesinde gerçek hayata fiziksel olarak yerleştirilmesi mümkün olmayan nesne ve olgular, artırılmış gerçeklikte sanal olarak algılanabilir hale gelir. Artırılmış gerçeklik sayesinde oluşan bu algı ortamları dijital oyunlar gibi eğlence odaklı kalmayıp hayat kurtaran bir ameliyattan, ameliyatı yapan doktorun eğitiminden, gerçekte var olmayan bir tasarım ürünü veya yapının görselleştirilmesinden, tarih öncesi çağda yaşamış olan bir yaratığın veya var olmuş bir mekânın canlandırılmasından, ambalajın etiketi üzerinden ürün detayına ulaşmaya kadar birçok alanda reel olarak kullanılmaya başlanmıştır. Teknolojik gelişmelerin paralelinde yaşam şekillerinin değişmesi ile yakın gelecekte bugün hayal bile edilemeyecek birçok ortamın artırılmış gerçeklik sayesinde insanlara sunulacağı açıktır. Bu çalışmanın amacını; artııılmış gerçeklik konusuna genel bir bakış açısı sunmak, son gelişmeleri incelemek, toplumsal yaşam üzerindeki etkilerini uygulama alanlarını dijital ortamlar açısından değerlendirmek oluşturmaktadır.

Anahtar Kelimeler: artırılmış gerçeklik, dijital teknoloji, mobil uygulamalar.

* Doktor Öğretim Üyesi, Karatay Üniversitesi, Sosyal ve Beşeri Bilimler Fakültesi 


\title{
A NEW WAY OF LIFE: AUGMENTED REALITY (AR)
}

\section{Bülent BiNGÖL*}

\begin{abstract}
Developments/changes in the field of technology directly or indirectly affect human life. The rapidly developing/changing software and hardware in the field of communication technology is not only determining people's ways of lives, their interaction with the environment, their individual leisure time activities, but it is also affecting every aspect of human life. The concept of "augmented reality" (AR) is being used in parallel with the technological developments in the fields of health, education, aviation, defense, architecture, marketing, publishing, travel, real estate, automotive, museology, advertising, entertainment and digital gaming. Augmented reality is the paradigm of the reflection of change in technology to a visual product since it creates a new perception of the surrounding by placing computer-generated digital elements such as sound, image, animation and hologram on the environment in real time via smartphones, tablets and virtual reality glasses. With this new enriched environment, objects and phenomena that cannot physically be placed in real environment become virtually perceivable. These perceived environments created by the augmented reality are not only being utilized in entertainment domains such as digital games but they are also being used in an array of areas from life-saving medical operations, education of doctors, visualization of a design product or a structure that does not exist in reality, animation of a creature that lived in prehistoric times or simulation of a historic space that no longer exists. With the life styles and technological developments changing in tandem, it is clear that in the future augmented reality will offer many environments to people that are hard to imagine today. This study aims to present an overview of the concept of augmented reality, to examine the recent developments in the field, to evaluate the effects of augmented reality on social life and its application areas in terms of digital media.
\end{abstract}

Key Words: augmented reality, digital technology, mobil applications.

* Lecturer/PhD, Karatay University, Faculty of Social and Humanity Sciences

\begin{tabular}{|c|c|c|c|}
\hline ISSN 2149-1909 & YIL 1 & Sayı 1 & Nisan 2018 \\
\hline
\end{tabular}




\section{Giriş}

Başkalarının gördüğünden daha fazla görebileceğiniz, başkalarının duyduğu müziklerden fazlasını dinleyebileceğiniz ve belki de başkalarının yapamayacağı şeylere dokunup, koklayıp, tadabildiğiniz bir teknolojiyi hayal edin. Gerçek dünya tecrübemizde tamamen sayısal öğeleri ve nesneleri algılayacak bir teknolojimiz olsaydı, tüm canlılar ve yapılar günlük faaliyetlerimizde bize yardımcı olurken, neredeyse bilinçsizce sadece jestler ve konuşmalarla etkileşim kuruyor olsalardı ne olurdu? Böyle bir teknoloji ile tamirci, bilmediği bir aleti tamir ederken talimatlara bakabilir; cerrahlar ameliyat yaparken, organların ultrason taramalarını görebilir; itfaiyeciler görünmez tehlikelerden kaçınmak için bina planlarını inceleyebilir, askerler insansız keşif uçaklarıyla düşman saflarındaki keskin nişancı pozisyonlarını görebilir, bizler yürürken sokaktaki her restoran hakkında yazılanları okuyabiliriz veya işe giderken dev canavarlarla savaşabiliriz (Feiner, 2002). Tüm bunlar aslında kulağa imkânsız gelse de, "artırılmış gerçeklik" sayesinde bugün artık algılanması mümkün olan olgulardır.

Artırılmış gerçeklik, yeni nesil gerçekliğe dayalı bir arayüz yaratmak için geliştirilen teknoloji olmakla birlikte; bugün dünyanın farklı yerindeki laboratuvarlardan çeşitli endüstriler ve tüketici pazarlarına doğru ilerlemektedir. Artırılmış gerçeklik, gerçek dünyayı, gerçek dünya ile aynı yerde var olan sanal (bilgisayar tarafından üretilen) nesnelerle destekler. 2007'de ortaya çıkan ve gelişmekte olan bu teknolojiyi, günümüzün akıllı telefonları ve artırımış gerçeklik tarayıcılarıyla, bu yeni ve heyecan verici insan-bilgisayar etkileşimini kucaklamaya başlıyoruz (Julier ve Bishop, 2002).

\section{Artırılmış Gerçeklik}

Artırımış gerçeklik, bilgisayar tarafında üretilen ses, görüntü, animasyon, hologram gibi dijital elemanları akıllı telefon, tablet ve sanal gerçeklik gözlükleri sayesinde bulunduğumuz ortamın üzerine gerçek zamanlı olarak yerleştirerek yeni bir algı ortamı oluşturur. Zenginleştirilmiş bu yeni ortam sayesinde gerçek hayata fiziksel olarak yerleştirilmesi mümkün olmayan nesne ve olgular, artırılmış gerçeklikte sanal olarak algılanabilir hale gelir. Artırılmış gerçeklik; yazı, resim ve video gibi bilgisayar ortamında oluşturulmuş materyalleri insanların gerçek dünyaları algılamalarının üzerine yansıtan geniş spektrumlu bir teknoloji olarak açıklanabilir.

Artırılmış gerçeklik, dijital materyalleri gerçek dünya nesnelerine yansıtan teknolojileri ifade eder. Bu tanım, saf bir sanal ortamdan gerçek ortama kadar geniş bir yelpazeye yayılmış teknolojileri tanımlamak olarak özetlenebilir (Milgram ve Kishino, 1994). Azuma'ya (1997: 355) göre artırılmış gerçeklik; gerçek ve sanal nesneleri gerçek bir ortamda birleştirir, etkileşimli olarak ve gerçek zamanlı olarak çalışır, gerçek ve sanal nesneleri her biri ile hizalar. 
Höllerer ve Feiner (2004: 2) ise artııılmış gerçekliği; gerçek ve bilgisayar tarafından üretilen bilgileri gerçek ortamda, etkileşimli ve gerçek zamanlı olarak birleştiren ve sanal nesneleri fiziksel nesnelerle hizalandıran bir sistem olarak tanımlarken; Ludwig ve Reimann (2005: 4) artırılmış gerçekliği, gerçek zamanlı olarak bir video kamera tarafından sağlanan gerçek duyulara sanal nesneler ekleyen insan-bilgisayar etkileşimi olarak kavramsallaştırır. Diğer yandan Zhou, Duh ve Billinghurst (2008: 193) artırılmış gerçekliği, bilgisayar tarafından oluşturulmuş sanal görüntülerin fiziksel nesnelerin üzerine gerçek zamanlı çakıştırılması olarak tanımlar.

\section{Artırılmış Gerçekliğin Kısa Tarihçesi}

Bilgisayar grafikleri öncüsü Ivan Sutherland ve Harvard Üniversitesi'ndeki öğrencileri ile Utah Üniversitesi öğrencilerinin oluşturduğu ilk AG prototipleri, 1960 'ı yıllarda ortaya çıktı ve 3D grafik sunmak için bir görme aracı kullandı. ABD'de küçük bir araştırmacı grubu Hava Kuvvetleri'nin Armstrong Laboratuvarı, NASA Ames Araştırma Merkezi, Massachusetts Teknoloji Enstitüsü ve Chapel Hill'deki North Carolina Üniversitesi, 1970'li ve 1980'li yıllarda araştırmaya devam etti (Tamura, 2002). Bu sırada Sony Walkman (1979), dijital saatler ve kişisel dijital organizatörler gibi mobil cihazlar tanıtıldı. Bu, 1990'lı yıllarda kişisel bilgisayarların her zaman giyilebilecek kadar küçük olmasından dolayı giyilebilir bilgisayar kullanımının yolunu açtı. (Matysczok vd. 2004: 269). Bugün, kişisel dijital asistanlar (PDA'lar), tablet PC'ler ve cep telefonları gibi artırılmış gerçekliği destekleyebilecek birçok mobil platform mevcut.

1990'ların başlarında Boeing Corporation'ın bilim adamları Caudell ve Mizell tarafından hazırlanan ve çalışanların kablolama işlemlerine yardımcı olması için deneysel bir artırılmış gerçeklik sistemi geliştirildi (Caudell ve Mizell, 1992: 659). Gerçek mobil AG'ye hala ulaşılamamıştı, ancak birkaç yıl sonra uzaysal ses bindirmeleri ile görme engelli kişilere navigasyon yardımını sunan bir GPS tabanlı dış mekan sistemi geliştirdi (Mann, 1997: 25). Çok geçmeden işlemci ve izleme aygıtları, mobil ayarlarda grafik yerleşimi destekleyecek kadar güçlü ve küçük oldu (Feiner, 1997: 74). Feiner, ziyaretçilerin binaları ve eserler görebilmesi için 3D grafiklere sahip tur rehberi bilgilerini kaydeden bir mobil artırılmış gerçeklik sistemi prototipi oluşturdu. Artırılmış gerçeklik 1990'ların sonunda ayrıcalıklı bir araştırma alanı haline geldi ve artırılmış gerçeklik üzerine uluslararası atölye ve sempozyum, karma gerçeklik üzerine uluslararası sempozyum ve ortamlarının tasarlanması atölyesi gibi çeşitli konferanslar başladı.

\section{Artırılmış Gerçeklik Teknolojisi}

Artırımış gerçeklik içeriği çeşitli şekillerde izlenebilir. Başlangıçta insanlar kendi web kameralarından QR kodları görüntülemelerine izin veren web uy- 
gulamaları ile karşılaşmış olabilirler. QR kodlarını kullanarak, 3D animasyonlar da dahil olmak üzere dijital bilgiler bir anlamda kağıt, kart ya da diğer yüzeylerdeki görüntülere eklenebilir. Sembol veya işaretler bir web kamerasının önünde tutulduğunda, artırılmış gerçeklik uygulamaları kullananlar bilgisayar veya konsol aracılığıyla, gerçek ortamları üzerine yerleştirilen dijital içeriği görüntüleyebilirler. İkinci yöntemde ise kullanıcılar başa takılan gözlüklerde yer alan ve gözün önüne denk gelen ekranlar sayesinde, gerçek ortam üzerine yerleştirilen dijital görüntüleri, birlikte ve gerçek zamanda izlerler. Üçüncü ve son yöntemde ise kullanıcılar, akıllı telefon veya tabletlerine yüklemiş oldukları artııımış gerçeklik uygulamaları sayesinde, kameralarını kullanarak gerçek ortamla dijital ortamın karışmış halini görmüş olurlar. Kullanılan akılIı telefon veya tabletlerin GPS, ivmeölçer ve dijital pusula özellikleri taşıması gerekebilir. Günümüzde Android ve iOS platformlarında birçok ücretsiz veya ücretli uygulama mevcuttur. Bu uygulamalar, oyundan alışverişe kadar birçok alanı içermektedir. Artırılmış gerçeklik mobil uygulamalarına en iyi örnek olarak tüm dünyayı saran Pokémon GO oyunu örnek gösterilebilir. Akıllı telefon ve uygulama sayesinde oyuncular, gerçek zamanda gerçek ortama yerleştirilmiş dijital görüntüleri izleyerek oyunu oynayabilmişlerdir.

\section{Uygulama Alanları}

Bilgiye erişmek için mobil bilgisayar teknolojileri ilerlerken; eğlence, sağlık, havacılık ve otomobil endüstrileri gibi pek çok alandaki bazı yaratıcı düşünceye sahip insanlar bunları uygulamak için faydalı yollar buluyorlar. Ayrıca mimarlık, mühendislik ve inşaat endüstrisi proje süreçlerini geliştirmek ve görselleştirmek için her geçen gün daha fazla bilgisayar tabanlı teknolojiyi benimseme yolunu seçmektedirler. Karmaşık yapı bilgilerini görselleştirmek, katılımcılara projeyi daha kolay anlayabilme ile tutarlı ve paylaşılan bir anlayış benimsemelerini sağlar. Artırımış gerçeklik; mimarlık, mühendislik ve inşaat endüstrisine araştırma aşamasında görselleştirme yoluyla önemli avantajlar sağlayacak ileri bilgisayar teknolojilerinden biridir. Artırılmış gerçeklik sadece endüstri ile sınırlı kalmayıp; sağlık, eğitim, havacılık, savunma, reklam, pazarlama, yayıncılık, seyahat, emlak, otomotiv, müzecilik, eğlence ve dijital oyun gibi alanlarda teknolojideki değişime paralel olarak kullanılmaktadır.

\section{Reklamcılık ve pazarlama}

Artırılmış gerçeklik birçok pazarlamacının rüyasıdır ve bir markanın, kullanııının kendi deneyimlerinden olumlu bir şekilde zorlandığı bir ortam yaratılmasına izin verir. Sadece birkaç isim vermek gerekirse; Coca Cola, Spotify ve Argos markalarının tamamı, reklamını yapmak için artırılmış gerçeklik teknolojisini kullandı. Artırılmış gerçeklik patlaması kendisini en çok reklamcılık ve pazarlama alanında göstermiştir. Potansiyel müşterilerin dikkatini ve ilgisini 
çekmek için yeni yollar arayan bazı şirketler, artırılmış gerçeklik uygulamalarını hayata geçirdi. Bu sayede kullanıcılar, görünüşte doğal hareketler ve el hareketleri kullanarak keşfedilebilen ve manipüle edilebilir alanlarını paylaşan sanal nesnelerle buluşma şansı elde etti. Örneğin üst sınıf otomotiv üreticileri, alışveriş merkezlerinde ve diğer kamusal alanlarda gerçek boyutlu artırılmış gerçeklik kullanarak sanal araçlarını sergilemeye başladı. Bir arabirim sayesinde, artırılmış gerçeklik eldivenleri veya diğer kontrollere ihtiyaç duymayan yayaların, gerçek zamanlı mekânsal hareketlerini sanal düğmelere geçiş yaparak; kapıları açmak, koltuk sırtlarını katlamak ve sanal model araçlarını döndürmek için kullanmalarına olanak tanıdı (Yuen, 2011: 1124). Oyuncaklar gibi daha küçük ürünler artık neredeyse tüm dünyadaki mağazalarda ve kiosklar$\mathrm{da}$, bazen entegre 3D animasyonlarla izlenebilir hale gelmiştir. Biraz daha sofistike kampanyalar, kullanııların akıllı telefonlarını kullanarak, mobilya gibi ürünlerin sanal modellerini çevrelerindeki herhangi bir yerde görüntülemek, döndürmek ve yeniden boyutlandırmak için kullanmalarına olanak tanıdı ve böylece izleyiciler, diğer eşyaların mevcut mobilyaları nasıl tamamlayacağına dair daha doğru görsel bir izlenim kazanabildiler. Diğer artırılmış gerçeklik uygulamaları, tüketicilere sanal kıyafetler veya aksesuarlar eklemek şeklinde açıklanabilir. Bunun önemli örnekleri, güneş gözlükleri veya saatler gibi aksesuar satan şirketlerin sanal soyunma odaları ve sanal aynaların yer aldığı kiosklarında görülebilir. Bu uygulamalar şirketler tarafından hem gerçek dünyada; hem de online perakende mekanlarında, müşteri alışveriş deneyimlerini zenginleştirmek için kullanılmaktadır. Tüketiciler yaptıkları seçimlerini sosyal medya aracılığı ile beğenilerini paylaşabilmekle birlikte artırılmış gerçeklik sayesinde satın alma işlemi de yapabilirler. Son olarak artırılmış gerçeklik market uygulamaları sayesinde fast-food ve medya şirketleri, popüler 3D karakterlerin meşrubat bardakları ve fast-food serilerindeki diğer ambalajlardan fırlaması şeklinde gelişen artııımış gerçeklik teknolojisini kullanmaktadırlar. Benzer şekilde Amerikan Posta Servisi, kullanıcılara uygun QR Kodu ile herhangi bir kâğıda yansıyan hologram formundaki kutularını görüntülemesine olanak tanır. Bu sayede müşteriler, gönderilmek istedikleri eşyaların boyutlarını kâğıda yansıyan sanal kutunun boyutuyla karşılaştırma olanağı bulmuş olurlar (Hampp, 2009).

\section{Mimarlık ve inşaat}

Artırılmış gerçeklik sistemleri, tasarımcılara, iş̧̧ilere, müşterilere ve potansiyel işverenlere gerçek proje alanının sanal görüntüsü içerisinde dolaşabilmelerine ve yapılması planlanan veya yapım aşamasında olan sanal bir tesisi/ binayı görmelerine ve deneyimlemelerine olanak sağlamak için kullanılabilir (Behzadan, 2008). Bu teknoloji ayrıca, inşaat sahasında çalışan iş̧̧ilerin yeraltı elektrik veya tesisat borularının sanal görüntülerini görmesini sağlayarak 
projelerin planlanmasında da yardımcı olabilir. Bu sayede, yapılan çalışmaların doğruluğu veya aksaklıklar artırılmış gerçeklik sayesinde görüntülenerek para ve zaman kazandıran önlem ve düzeltmelerin yapılmasına imkân tanınmış olur. Tüm veriler, bir üç boyutlu modelden ve yapıya dair ilişkilendirilmiş dijital bilgilerden gelmektedir. Kısacası artırılmış gerçeklik teknolojisinin kullanımının, problemleri azaltmasının yanı sıra; mimari ve inşaat alanında zamandan ve paradan tasarruf sağlayabileceği çeşitli yollar vardır.

\section{Eğlence ve oyun}

Artırılmış gerçeklik sistemi kullanılarak hiçbir özel ekipman kullanmadan gerçekleştirilen konser ve dans gösterileri, Japonya başta olmak üzere birçok ülkede görülmüştür. Daha geleneksel artırılmış gerçeklik teknolojisini kullanan kitap endüstrisi, kitabın sayfalarını kaplayan hareketli görüntüler ve bunlarla etkileşim halinde olan müzik ve ses efektlerinin olduğu artırılmış gerçeklik kitaplarını çoktan kullanıılara sunmuşlardır. Başka bir yaklaşımla, sesle desteklenmiş resimlerin veya 3D animasyonların sayfanın üzerine geldiğinde hareket ettiği 'pop-up' kitaplar olarak kendini göstermiştir (Billinghurst vd. 2001: 745). Ayrıca, elektronik oyun ve sosyal medya endüstrisi, kapsamlarını AG teknolojilerini de dâhil edecek şekilde genişletmeye başlamışlardır.

Akıllı telefon uygulamaları ve taşınabilir oyun konsolları, kullanıcıların çevrelerindeki gerçek ortamda olmayan sanal peri ve diğer mitolojik yaratıkları izlemesine ve toplamasına izin veren oyunları piyasaya sürdü. Bu tür oyunlara en iyi örnek, çıktığı günden itibaren satış rekorları kıran ve dünyayı saran Pokémon GO olarak verilebilir. Raju'ya (2009) göre bu tür artırılmış gerçeklik oyunları stres azaltma konusunda dikkat çekmektedir. Diğer yandan mobil uygulamalar sayesinde iPad kullanıcıları, uzaktan kumanda edilebilen helikopter veya dron uçurabilmektedirler.

Artırımış gerçeklik oyunu, oyunun görsel ve işitsel içeriğini kullanıcının ortamıyla gerçek zamanlı olarak bütünleştirmektir. Saran bir ortam yaratmak için genellikle ayrı bir oda veya sınırlı alan gerektiren sanal gerçeklik oyunundan farklı olarak, artııımış gerçeklik oyunları mevcut ortamı kullanır ve içinde bir oyun alanı oluşturur. Sanal gerçeklik oyunları özel sanal gerçeklik başıkları gerektirirken, sadece bazı artırılmış gerçeklik sistemleri bunları kullanıyor. Artırılmış gerçeklik oyunları genellikle akıllı telefonlar, tabletler ve taşınabilir oyun sistemleri gibi cihazlarda oynanabilir.

Bilgi işlem gücü ve teknolojideki son gelişmelerle birlikte, artırılmış gerçeklik oyun uygulamaları yükselişe geçti. Başa giyilen sistemler artık uygun fiyatlı, işlem gücü yüksek ve her zamankinden daha kullanışlı. Pokémon GO diyebilmeniz için, mobil cihazınızla çalışan bir AG oyununa atlayabilir, efsanevi yaratıkları günlük manzaranızın üzerine koyabilirsiniz. Ingress, SpecTrek, 
Temple Treasure Hunt, Ghost Snap AR, Zombies, Run!, AR Invaders sadece popüler Android ve iOS oyunlarından bazıları. Artırılmış gerçeklik oyunları, oyuncuların veya oyun ustalarının sanal insanlar ve nesneler yaratmalarına ve daha sonra bu yapıları gerçek dünyadaki belirli konumlara bağlamalarına izin verir. Oyuncular daha sonra, gerçek dünya üzerindeki ilgili konuma yaklaştığında görünen bu dijital yaratıklar ve nesnelerle etkileşime girebilirler.

Oyun için devrim niteliğindeki artırılmış gerçeklik uygulaması olarak düşünülen Pokémon GO, bir akıllı telefonun kamera, cayroskop, saat ve GPS'ini konuma dayalı artırımış gerçeklik ortamı sağlamak için kullanılır. Mevcut ortamın bir haritası ekranda görüntülenir ve çim hışırtısı bir Pokémon varlığına işaret eder; dokunmatik ekrana dokunulduğunda ekran yakalanmış olur. AG modunda, kullanıcının gerçek dünyasında Pokémon ekranı görüntülenir. Artırımış gerçeklik oyunlarının kullanıldığı veya kullanımının yakın zamanda artması düşünülen diğer bir alan eğitim alanıdır. Çoğu zaman eğitimciler, öğrencilerin sınıf ortamında kavramlarını kolayca kavradıklarında yardımcı olması için oyunlardan yararlanırlar. Artırılmış gerçeklik teknolojisinin yardımıyla, gerçek dünyada bulunan ve ağa bağlı verilerle zenginleştirilen oyunlar, eğitimcilere ilişkileri ve bağlantıları göstermek için güçlü yeni yollar verebilir.

Artırımış gerçeklik oyunları eğitimcilere yeni görsel ve yüksek etkileşimli öğrenme biçiminden faydalanma fırsatı sunar. Örnek olarak SimSnails, ziyaretçilerin doğal seleksiyon ve evrim kavramlarını öğrenmelerine ve bunlarla deney yapmalarına yardımcı olan interaktif bir görselleştirme ve öğretim aracıdır (Kapp, 2009).

\section{Tip}

Artırılmış gerçeklik teknolojisi tıp alanında gerçekleştirilen ameliyat ve tıbbi müdahalelerin başarısını artırmakla kalmayıp; verimliliğine, güvenliğine ve etkinliğine de destek olmuştur. Ayrıca artırılmış gerçeklik, tıp alanında yeni gelişmelerin ve icatların yaşanmasını da sağlamıştır. Artırılmış gerçeklik sistemleri cerrahları, ameliyat öncesinde, sırasında ve sonrasında navigasyon ile oryantasyon bağlamında destekleme potansiyeline sahiptir. Tıbbi artırılmış gerçeklik uygulamaları, daha preoperatif görüntüleme çalışmalarına olanak tanıyarak, doktorlara ve cerrahlara CT, MRI ve ultrason verilerinden derlenmiş hastaların dahili anatomisinin holografik görünümünü incelemelerine izin vererek; cerrahi prosedür planlandıktan sonra bu sistem, gerçek zamanlı olarak sanal görüntüler oluşturmak suretiyle akan görüntüler kullanabilmektedir. Görsel büyütmenin ötesinde AG sistemleri, açık ameliyat yapmak zorunda kalmadan, cerrahların tümör hissetmesini veya dokunarak hastanın durumunu keşfetmesini sağlamak için haptik cihazları (dokunma veya titreşim geri bildirim araçlarını) entegre edebilir. Dahası; güvenilir ve tutarlı geribildirimi ile 
birleştirilmiş artırılmış gerçeklik sistemi, daha zor ameliyatları daha az müdahaleyle gerçekleştirebilme imkanı tanıyabilir (Samset vd. 2008). Diğer yandan tıp öğrencileri kontrollü bir ortamda ameliyat uygulamak için artırılmış gerçeklik teknolojisini kullanırlar ve görselleştirmeler, hastalara karmaşık tıbbi durumların açıklanmasında yardımcı olur. Artırımış gerçeklik, cerrahın duyusal algılamayı geliştirmesiyle bir operasyonun riskini azaltabilir.

\section{Ordu}

Askeri alanda kullanılan ve en çok bilinen artırılmış gerçeklik sistemi, helikopter pilotlarının başlıklarına monte edilmiş görüntüleme sistemleridir. Bu başlıklar sayesinde savaş pilotları yönerge, harita ve düşman noktalarını görme olanağı elde eder. İstendiği takdirde görüntüler, aracın gösterge paneline veya kokpit penceresine yansıtılır. Bu görüntüleme sayesinde pilotlar, merkezden gelen verileri 3D olarak izleyebilirler. Görüntülerde tehlike, kritik nokta ve unsurlar farklı renklerde kodlanıp yansıtılarak askerlerin hata yapmasının önüne geçilir ve daha tutarlı manevra yapmaları sağlanır (Sisodiaa vd. 2007). Ayrıca benzer sistemler, muharebe alanında yaya olarak hareket halindeki askerlerin başlıklarına da monte edilerek, aynı görüntüleri bireysel olarak almaları sağlanmaktadır. Başlığa monte gösterge kara birlikleri tarafından kullanılarak; düşman konumu gibi kritik veriler, askere görüş hatları dahilinde sunulabilir. Bu teknoloji, askeri eğitim amaçlı simülasyonlar için de kullanılır.

\section{Seyahat}

Artırılmış gerçeklik ayrıca seyahat ve turizm uygulamaları da yapmaktadır. Yerel işletme rehberi Yelp, akıllı telefonların belirli bir yere yönlendirildiğinde, yerel kuruluşlarla ilgili kullanıcı bilgilerini veren Yelp Monokle adlı bir artırılmış gerçeklik özelliğine sahiptir. Bir diğer kullanışı uygulama Google tarafından geliştirilen ve şimdi Google Translate'in bir parçası olarak dahil edilen Word Lens'tir. Uygulama, yabancı bir işaret doğrultulduğunda, metni kullanıcının ana diline çevirir. Gezi ve turizm endüstrilerinde artırılmış gerçeklik özelliğine sahip uygulamaların bir müzedeki eserlerin görüntüsünü gerçekçi figürlerle zenginleştirme yeteneği, teknolojinin doğal bir kullanımıdır. Artırılmış gerçeklik kullanılarak geliştirilen ve kamera ile donatılmış akıllı telefon kullanan turistler kendilerini, tarihi mekânlarda yürüyerek, ekranda gerçek ortam ve figürlerle aynı ortamı paylaşıyor olarak görebilmektedirler. Bu uygulamalar, online bir veri tabanından verileri aramak için GPS ve resim tanıma teknolojisini kullanmaktadır. Kullanıcılar bu teknoloji sayesinde tarihi bir mekânın 100 yıl önce nasıl göründüğünü, sahip oldukları mobil teknoloji vasıtasıyla, artırılmış gerçeklik görüntüleri eşliğinde dolaşma imkânı bulmaktadırlar.

Sosyal medya, kullanıcıların gerçek zamanlı gerçek dünya konumları hakkında, araç kullanımı ve ilgi duyduğu aktiviteleriyle ilgili bilgileri zaten kullan- 
maktadır. Artırılmış gerçeklik sayesinde bu sanal holografik işaretler, belirteçler, kılavuz çizgiler, kayan oklar ve diğer ipuçları gibi görünür hale gelecektir. Bu mevcut hizmetlerin basit duyusal genişlemesinin ötesinde artırılmış gerçeklik, kullanıcılara bölgeyle ilgili turistik ve işletme bilgilerini gösteren daha yeni, daha kapsamlı arayüzlerle çevresi ve gerçek konumları hakkında bilgi vermektedir. Kullanıcının tek yapması gereken akıllı telefonlarının GPS özelliğini veya kamerasını kullanmak olacaktır. Buna ek olarak; otomobil üreticileri arabaları dahili monitör, entegre kablosuz veya uydu internet ve artırılmış gerçeklik pencereleri ile kızılötesi ve ultraviyole algılama ve çevresindeki gerçek dünya ortamının sanal-holografik görüntüleme sağlayan, yüksek teknoloji ürünü askeri uçaklarda mevcut mobil cihazlar kullanma planlarını sürdürmektedir (Dugdale, 2010).

\section{Eğitim}

2009'dan beri The British Museum, çocuklara Parthenon galerisini anlamalarına yardımcı olmak için artııımış gerçekliği kullanmaktadır. Genç galeri ziyaretçileri, Samsung tabletlerini kullanarak, bir hikâye anlatmak için müzenin koleksiyonundaki heykelleri kullanan 'A Gift for Athena' adlı bir artırılmış gerçeklik oyunu oynayabilmektedirler. Artırılmış gerçeklik teknolojisi MOOC (Massive Open Online Course) sayesinde sınıfa adapte edilerek, öğrenci ve öğretmenlerin su döngüsünü keşfetmeleri sağlanmıştır. Araştırmacılar, artırılmış gerçeklik teknolojisinin öğretme ve öğrenmeye olası büyük faydaları olduğunu düşünmektedir. Yuen, Gallayanee ve Johnson'a (2011: 127) göre artırılmış gerçekliğin: a) uyarma ve öğrencileri farklı açılardan sınıf materyalleri keşfetmeye motive etme, b) öğrencilerin gerçek dünyanın ilk elden tecrübesini kazanamayacakları konuları öğrenmesine yardımcı olma, c) öğrenciler ve öğretmenler arasındaki işbirliğini geliştirme, d) öğrencinin yaratıcılığını ve hayal gücünü arttırma, e) öğrencilerin öğrenmelerini kendi hızlarında ve kendi patikalarında kontrol etmelerine yardımcı olma, f) çeşitli öğrenme stillerine uygun otantik bir öğrenme ortamı yaratma konusunda katkıları vardır. Dünyada birçok üniversite, daha etkin bir eğitim ortamı yaratmak amacıyla tıp, mühendislik, mimari gibi bölümlerinde artırılmış gerçeklik gözlükleri sayesinde öğrencilerine, gerçek hayatta görme veya deneyimleme imkânları olmayan ortam ve uygulamaları tecrübe etme şansı vermiştir.

\section{Sonuç}

Artırılmış gerçeklik, bilgi işleme ve görüntü teknolojilerindeki ilerlemeler paralelinde gelişmeye devam edecektir. Eğlenceden, insanlık yararına olan sayısız alanda varlığını sürdüreceği, bugün geldiği nokta ile kıyaslanırsa görülmektedir. Yeni çıkan her teknoloji gibi artırılmış gerçekliğin insan hayatını yönlendirmede etkisi olduğu şüphe götürmemekle birlikte, olumlu veya 
olumsuz etkileri ilerleyen zamanlarda görülecektir.

Artırılmış gerçeklik, akıllı telefon uygulamalarının ve oyunların yüzünü değiştiren bir teknolojidir. Artırılmış gerçeklik, gerçek dünyadaki görüşleri güçlendirmek için, kullanıcılara ortamları hakkında daha fazla bilgi veren dijital görüntüler ve veriler ekleyerek, gerçekliği simule etmeye çalışan sanal gerçekliğin ötesine geçmiştir. Artırılmış gerçeklik uygulamaları, kullanıcılarını cezbeden farklı bir alan kazandırdıkları için muazzam bir hızla büyümeye devam edecektir.

Artırılmış gerçeklik uygulamaları da, farklı özellikleri sayesinde insanların daha önce faydalanmalarının imkânsız olduğu bazı alanlarda yaşam kaliteleri ve yaşama biçimleri üzerinde olumlu etkiler bırakmaktadır. Özellikle tıp ve eğitim gibi insan hayatını direkt etkileyen alanlarda kullanılan AG uygulamaları, insanların hayatını kurtarmak ve yaşam kalitelerini artırmakla kalmayıp; bu misyonu üstlenen doktorların daha yetkin eğitilmelerine de olanak sağlamaktadır. Eğlence, seyahat, mimari/inşaat ve reklam gibi ticaret odaklı alanlarda kullanılan uygulamalar insanların yaşam kaliteleri ve yaşama biçimlerini etkilemekle kalmayıp, oluşan bu yeni sektör sayesinde sermaye, istihdam ve vergi artışının yükselmesine katkıda bulunarak, toplumsal kalkınmanın hızlanmasına olumlu etkide bulunmaktadır.

\section{Kaynakça}

Azuma, R. T. (1997). A Survey of Augmented Reality. Presence. 6(4). 355-385.

Behzadan, A. H. (2008). ARVISCOPE Georeferenced Visualization of Dynamic Construction Processes in Three-Dimensional Outdoor Augmented Reality. (Yayınlanmamış Doktora Tezi). Michigan: Department of Civil and Environmental Engineering-The University of Michigan.

Billinghurst, M., Kato, H., Poupyrev, I. (2001). "The MagicBook: A Transitional AR Interface". Computers and Graphics. 25(5). 745-753.

Caudell, T. P. ve Mizell, D. W. (1992). "Augmented Reality: An Application of Heads-Up Display Technology to Manual Manufacturing Processes". Proc. Hawaii Int'I Conf. on Systems Sciences. Kauai: IEEE CS Press. 659669.

Dugdale, A. (17 Mart 2010). GM to Use Augmented Reality Tech for Safer Driving. http://www.fastcompany.com/1586608/gm-to-use-augmented-reality-tech-for-safer-driving. 7 Şubat 2018.

Feiner, S. K. (2002). "Augmented Reality: A New Way of Seeing". Scientific American. 286(4). 48-55.

Hampp, A. (19 Kasım 2009). Marketers Hop on Augmented Reality Bandwagon to Promote 'Avatar'. http://adage.com/madisonandvine/article?article_id=140661. 7 Şubat 2018. 
Höllerer, T. H., ve Feiner, S. K. (2004). “Mobile Augmented Reality". H. A. Karimi ve A. Hammad (ed.) Telegeoinformatics: Location- Based Computing and Services. (392-421). USA: CRC Press.

Julier, S. ve Bishop, G. (2002). "Tracking: How Hard Can It Be?". IEEE Computer Graphics and Applications. 22(6). 22-23.

Kapp, C. (21 Haziran 2009). SimSnails [Video]. http://www.youtube.com/ watch?v=4JTCabfxEcw. 10 Ocak 2018.

Ludwig, C. ve Reimann, C. (2005). "Augmented Reality: Information at Focus". Cooperative Computing \& Communication Laboratory. 4(1). 1-12.

Mann, S. (1997). "Wearable Computing: A First Step Toward Personal Imaging”. Computer. 30(2). 25-32.

Matysczok, C., Radkowski R., Berssenbruegge, J. (2004). "AR-Bowling: Immersive and Realistic Game Play in Real Environments Using Augmented Reality". ACE'04: Proc. Int'l Conf. on Advances in Computer Entertainment Technology. Singapore: ACM Press. 269-276.

Milgram, P., ve Kishino, F. (1994). "A Taxonomy of Mixed Reality Visual Displays". IEICE Transactions on Information Systems. 77(12).

Raju, P. (21 Ekim 2009). 15 Stunning Augmented Reality Apps for iPhone. http://techpp.com/2009/10/21/15-stunning-augmentedreality-iphone-apps/. 12 Ocak 2018.

Samset, E., Schmalstieg, D., Vander Sloten, J., Freudenthal, A., Declerck, J., Casciaro, S., Rideng, Ø., Gersak, B. (2008). "Augmented Reality in Surgical Procedures". Proc. SPIE. 68(6).

Sisodiaa, A., Bayerb, M., Townley-Smith, P., Nash, B., Little, J., Casarly, W., Gupta, A. (Mayıs 2007). "Advanced Helmet Mounted Display (AHMD)". Proc. SPIE 6557: Head- and Helmet-Mounted Displays XII: Design and Applications. doi:10.1117/12.723765.

Tamura, H. (2002). "Steady Steps and Giant Leap Toward Practical Mixed Reality Systems and Applications". VAR'02: Proc. Int'I Status Conf. on Virtual and Augmented Reality. Leipzig: Germany.

Yuen, S. (25 Şubat 2011). Ford of Britain Launched an AR Campaign. http:// steveyuen.org/blog/?p=1124. 18 Ocak 2018.

Yuen, S., Gallayanee, G., Johnson, E. (2011). "Augmented Reality: An Overview and Five Directions for AR in Education". Journal of Educational Technology Development and Exchange (JETDE). 4(1). doi: 10.18785/ jetde.0401.10.

Zhou, F., Duh, H. L., Billinghurst, M. (2008). "Trends in Augmented Reality Traching. Interaction and Display: A Review of Ten Years in ISMAR". Mixed and Augmented Reality. ISMAR 7th IEE/ACM International Symposium. (193-202). Cambridge: IEEE. 